\title{
Hierarchies of Masculinities: An Analysis of the Characters in the Indian Web Series, Paatal Lok
}

\author{
Rupa Peter ${ }^{1 *}$ (D), Muskan $\operatorname{Raj}^{1}{ }^{1}$ (D)
}

${ }^{1}$ Jyoti Nivas College Autonomous, INDIA

*Corresponding Author: rupapeter@gmail.com

Citation: Peter, R., \& Raj, M. (2021). Hierarchies of Masculinities: An Analysis of the Characters in the Indian Web Series, Paatal Lok. Mediterranean Journal of Social \& Behavioral Research, 5(2), 29-33. https://doi.org/10.30935/mjosbr/10916

\begin{abstract}
Media and society are interdependent entities that are suspended seamlessly in a state of blissful co-existence where one feeds the other and vice versa. More so, when it comes to gender issues, wherein, media's narrative is shaped by societal norms and society imbibes a large part of its gender conversations from media. Media's representation of the masculine has largely been dictated by inherent patriarchal norms and the classic hegemonic patterns dominant in media narratives. However, as R.W. Connell recognised, there exists a diverse range of masculinities and its own hierarchical structure which is also represented through media content.

Over-the-top (OTT) platforms are gaining ground in India's crowded media scene because of factors like accessibility, affordability and variety of content. Indian content on OTT platforms are targeted at the young, urban, upwardly-mobile Indian middle class and are largely slick productions with hard-hitting, original storylines and closer-to-reality characterizations. Paatal Lok is one such very popular crime drama that has a primarily masculine narrative. This study uses R.W. Connell's three structures of gender relations: labour, power and cathexis to understand the representation of masculinities in Indian OTT media across class structures by identifying the hierarchies of masculinities in the Indian web series, Paatal Lok. The study uses qualitative techniques in the form of discourse analysis to gain further insight into the representation of different gradations of masculinities in contemporary Indian media.
\end{abstract}

Keywords: masculinities, hierarchies of masculinities, RW connell, gender studies, Indian web series, OTT platforms, hegemonic masculinity

Received: 1 Apr. $2021 \bullet$ Accepted: 11 May. 2021

\section{INTRODUCTION}

Gender discourse, predominantly, revolves around a binary equation (Rushton et al., 2019). A binary that is purported by biological characteristics and reinforced by a socially constructed gender identity (Von Doellinger, 2018). This binary is considered the status quo in the mainstream but is found unacceptable among the marginalized minorities who consider gender to be a spectrum (Darwin, 2017).

Within the realm of gender discourse rests the concept of hierarchies of gender (Miller, 1993). Patriarchy places one gender over the other wherein the men dominate and women are subordinate in a number of ways (Bhasin, 2006). This is a form of traditional discourse that is consistently questioned and opposed by all forms of feminism (Budig \& Jones, 2008). Feminism purports social, political, economic and personal equality among the sexes. However, within gender, power equations vary. There are gradations inherent within gender that is not subtle. Within the masculine, there exists a model of multiple masculinities - a pluralistic set of gender practices. Masculinities refers to the hierarchy of males within genderism based on certain traits and characteristics that define their identity and standing in a social set-up (Pascoe, 2007).

With the COVID-19 pandemic and the subsequent series of lockdowns in India, Indians have tuned into OTT (Over-The-Top) platforms for their dose of entertainment (Mathew, 2020). Paatal Lok is an intelligently written, fast-paced, and engrossing (Gupta, 2020) fictional crime thriller and a riveting tale that delves into the 'whydunnit' of crime and is packaged as a perfect morality tale, interspersed with liberal references of Hindu mythology (Malik, 2020). Its neo-noir narrative is an intense, gritty and satirical sneakpeak into the world of mucky liaisons between media, police and politics in India. The show premiered on Amazon Prime Video (OTT) on May 15, 2020. Apart from focusing on many subaltern themes such as caste, religious and class divisions; issues related to social, religious and sexual minorities in India (Banerjee, 2020), the series has several male characters who are representative of different forms of masculinities in the country. This study uses R.W. Connell's gender order theory to understand the hierarchies of masculinities in the Indian web series, Paatal Lok. In doing so, the study seeks to gain further insights into the 
representation of different gradations of masculinities in Indian entertainment streaming media.

\section{THEORETICAL FRAMEWORK}

Gender theorists like Jill Mathews have stressed upon a hierarchical relationship in gender based on the struggles and power strategies and contradictions and unintended consequences of social groups and individuals (Mambrol, 2017). R.W. Connell has integrated gender order into social structures and discusses the concept of hierarchies within gender. The most common position within the order of masculinities is the identity of the dominant hegemonic masculinity; which in itself presents its own varied shades. R.W. Connell discusses three structures of gender relations: labour, power and cathexis. Labour refers to the division, segregation and discrimination in work. Power refers to authority and control and cathexis refers to 'sexual social relationships' (Connell, 1987). In this study, Indian streaming media's representation of gender order within masculinities is studied using R.W. Connell's three structures of gender relations: labour, power and cathexis.

\section{LITERATURE REVIEW}

While studying the construction of masculinity through images in lifestyle magazines in Croatia Loncar, Vucica, and Nigoevic (2016) found that these magazines represent a homogenized group of ideal men mostly white, muscular, and rich to represent success or prestige to the consumer. The portrayal of men's images as muscular, good looking or successful signifies the need for a 'good looking image' of a man to conceptualise masculinity.

Wong et al. (2010) while studying the content of the journal, Psychology of Men and Masculinity between the years 2000 and 2008 identified men's violence as one of the most problematic aspects of the male role. The top three most frequently addressed topics with regard to men and masculinity were mental health, relationships and violence. While discussing gender stereotypes in media, Devi (2018) emphasises on the age-old prevalence of hegemonic masculinity in Manipuri media. Men are represented as dominant, independent, intelligent and decisive whereas the women are shown as naive, dependent and less intelligent in Manipuri films, advertisements, print media and radio.

Engstrom (2016) while examining how the NBC comedy series Parks and Recreation utilizes alternative forms of masculinity through its male characters to counter traditional hegemonic masculinity and purports a 'new man' who embraces feminism through osmosis; is androgynous or even genderless; emotional, kind, intellectually curious and compassionate. The 'new man' is a broad representation of R.W. Connell's positive masculinity that moves into a new, more egalitarian version of masculinity.

Susilo (2017), while critically reviewing masculinity discourse in media text related to violence on online news portals found that online news portals perpetuate masculine discourse. Online news portals and their acquired resources strengthen violence labelling as a part of masculine domination over the feminine. Trujillo (1991) while studying media representations of Nolan Ryan and American sports culture states that Ryan is represented as an embodiment of male athletic power in mediated sport. He is also represented as an ideal image of the capitalist worker, as a family patriarch, as a white rural cowboy, and as a phallic symbol in media and commodified as a symbol of hegemonic masculinity. Cutler (2007) while analysing masculinities in advertisements in seven popular men's magazines uncovered seven dimensions of masculinities which vary in their levels of compliance to the hegemonic mould. The seven dimensions of masculinities identified are lover, athlete, military man, tough guy, sexy man, male model and pretty boy. This, according to Cutler (2007) could mean that society is becoming more accepting of diversity and men do not have to fit into the traditional hegemonic mould.

\section{RESEARCH METHODOLOGY}

\section{Statement of the Problem}

Indian web series are fresh, bold and tailored for the urban, techsavvy Indian youth. They showcase an eclectic range of characters who are urbane, whose depictions are very close to reality and whose language is a mix of Hindi and English (Verma, 2018). A study of the characters of Paatal Lok, a popular web series on the basis of their hierarchy in masculinities spectrum would identify Indian streaming media's depiction of masculinities. Since media can be considered as a metaphorical mirror (McQuail, 2010), reflecting myriad events in a society, this study would shed light on societal view of masculinities in India.

\section{Objective of the study}

To understand the representation of masculinities, its varied hierarchies, based on socio-economic-political background, in the Indian streaming entertainment media.

\section{Research Design}

This study uses qualitative research techniques in the form of a discourse analysis to understand the hierarchies of masculinities in the season one of Paatal Lok. The study analyses seven biologically aligned male characters that are primary to the plot of Paatal Lok.

This study uses a non-linear yet progressive data coding process using Neuman's three-step coding process for the analysis. The coding process involves open coding of media text involving the seven characters across the nine episodes of season one, on three criteria: labour, power, and cathexis. Dialogues, tone of delivery, body language, costumes, exhibited personality traits for each of the seven characters were analysed within the framework of their socio-economic-political context in the web series.

The second stage is the axial coding where connections between codes were identified to create a frame of meaning for each structure. In selective coding, connections between the three structures of gender relations for each character were identified to arrive at their hierarchical role in the masculine order.

\section{FINDINGS}

For the study, seven characters with male biological identities in Season One of the web series, Paatal Lok were analysed. The findings are discussed below.

Hathi Ram Chaudhary, Inspector, Outer Jamuna Paar region 


\section{R. W. Connell's Structures of Gender Relations}

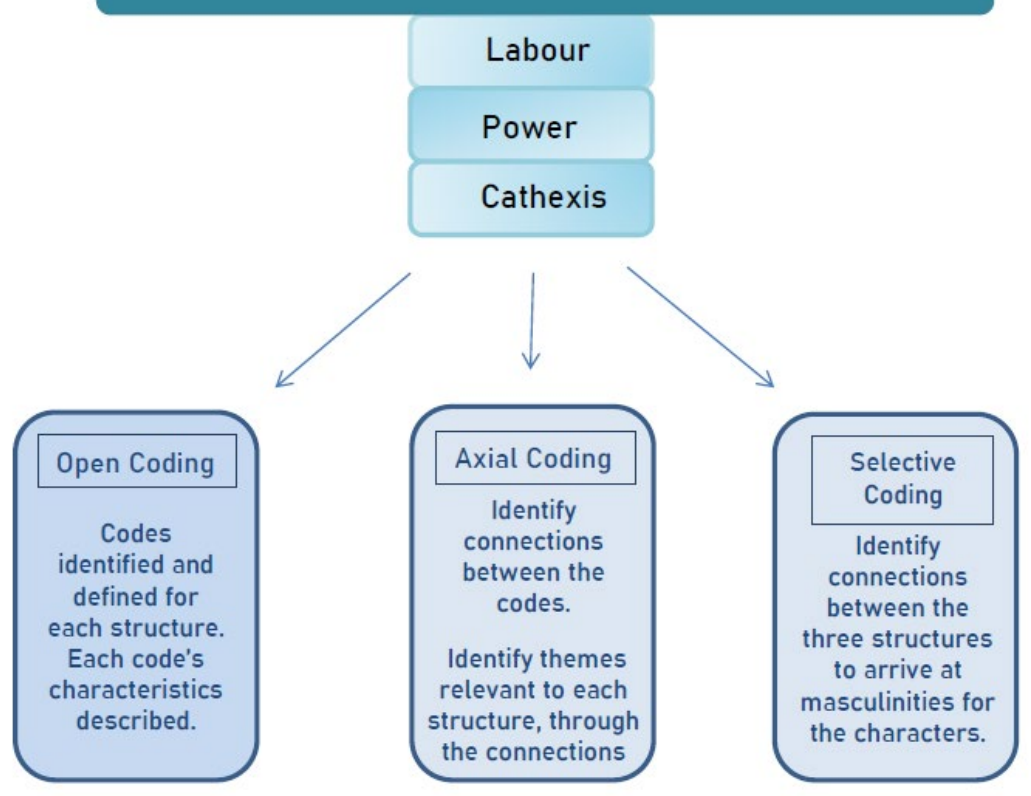

Figure 1. Three-step coding process

Hathi Ram Chaudhary is tough, self-critical, rebellious, impulsive, reckless and persevering. He seeks social recognition and is learning and evolving on a personal level as the series progresses. Hathi Ram Chaudhary tries to fight the system that undermines him and in doing so finds his purpose. With labour, Hathi Ram Chaudhary evolves into a seeker of truth. Hathi Ram Chaudhary gains power through understanding of self. A rough exterior entrenched in patriarchy with innate warmth and humaneness defines his cathexis.

Hathi Ram Chaudhary is representative of Connell's classic hegemonic male. However, Hathi Ram's willingness to understand grow, adapt and evolve an emotional perspective in both his professional and personal life puts him on the borderlines between hegemonic and complicit masculinity - a type of hybrid that veers towards a more positive idea of masculinity.

\section{Sanjeev Mehra, Television Journalist (Editor, NBW News)}

Educated, elite, powerful, influential, shrewd, power-hungry, dominant and manipulative, Sanjeev Mehra fits into the classic 'survival of the fittest' mould. He discards his idealism for power and position, in order to survive and garner a strong position of power. Labour for him is a means to an end - acquisition of power. Narcissism and a patriarchal mindset define his cathexis.

$\mathrm{He}$ is a classic representation of R.W. Connell's hegemonic masculinity with all its characteristics of a dominant social role in terms of status, economic dominance, need for power and control, heterosexuality and a strong patriarchal dividend.

\section{Imran Ansari, IAS aspirant and Sub-Inspector, Outer Jamuna Paar}

Imran Ansari is an idealistic, play-by-the-rules, soft-spoken, urban male who is driven by values of hard work and friendship. He is lowkey, reliable, quietly ambitious and committed to his professional growth. He has limited powers due to his lower status on the professional front and due to undertones of religious discrimination. $\mathrm{He}$ remains stoic when disparaged and maintains the power status quo by not reacting to forces around him. He enjoys what Connell calls the patriarchal dividend and seeks to play by the rules in an inherently hegemonic masculine system in order to reap its physical, symbolic and material benefits. He is representative of R.W. Connell's complicit masculinity.

\section{Tope Singh a.k.a. Chaaku, Small-time criminal}

Tope Singh is an aggressive, brash, foul-mouthed, gun-trotting macho guy with a penchant for living dangerously and who uses violence and bloodshed to fight caste-centric oppression and establish power. He has an obsessive personality in life, and in love. He revels in sexist slurs and has a strong patriarchal outlook. Caste discrimination and lack of social standing makes Tope Singh an ideal candidate for R.W. Connell's marginalized masculinity. However, Tope Singh also represents a machismo-driven masculinity that refuses to adhere to societal norms but seeks power through violence. He represents resistant masculinity that rebels against his marginalized status and tries to create a space in the hegemonic masculine milieu.

\section{Vishal/Hathoda Tyagi, Hitman}

Vishal/Hathoda Tyagi is a dog-lover and an underdog who yields power through brutality and cold-blooded violence. He is silent, stoic, loyal and remorseless. Vishal/Hathoda Tyagi displays all the characteristics of a culturally hegemonic male in terms of the brute force that he uses to quell opposition; his patriarchal need to avenge his sisters' assault, his callous gravitation towards extreme violence, his lack of fear or remorse and his emotionally supressed demeanour.

$\mathrm{He}$ is also a classic representation of marginalized masculinity wherein he has a negatively charged social standing (as an accused in 45 murders) which limits his upwardly climb, on the masculine gender order. He is representative of a deviant form of hegemonic masculinity wherein he is a hegemonic male with characteristic power, aggression 
and emotional suppression but falls short because his actions which are divergent and undesirable within societal boundaries.

\section{Mary Lyngdoh a.ka. Cheeni, Masseuse}

A transgender, Mary has had a hard abusive childhood in the streets but is trying to work her way up the social ladder. Her mission is to earn enough for sex change surgery. Mary is powerless and vulnerable. Mary's lack of power has three causes: One, she is a transgender who seeks to be identified as a woman and hence by default is assumed to be a prostitute; two, there is Mary's backstory of child sexual abuse and three, she is called a Nepali and Cheeni on account of her mongoloid features. Mary's sexuality works to her disadvantage. She is subjected to male gaze, lewd gestures and transphobic comments.

Mary Lyngdoh a.k.a Cheeni is a classic representation of R.W. Connell's subordinated masculinity wherein her biological gender is taken into account by a society that denies her a right to choose her gender.

\section{Kabir M., Driver}

Kabir M is sensitive, creative, quiet and afraid. Kabir M. chooses to hide is religious identity and is a powerless victim of religious violence. Kabir M. is representative of marginalized masculinity that opts to hide rather than fight back. This is the prime difference between Tope Singh who is violent and rebels whereas Kabir M. meekly accepts, camouflages and tries to move on. He has reconciled with his stand in society and tries to blend in. He can be termed as representative of a reconciled or negotiated masculinity.

\section{Hierarchies of Masculinities in Paatal Lok}

In the web series, we have the dominant hegemonic male, the journalist, Sanjeev Mehra at the top of the hierarchy. Hath Ram Choudhary who exhibits traits that are partly dominant hegemonic and at times, complicit; along with the ability to evolve for the better embodies positive masculinity. This is followed by complicit and resistant masculinity which share the same space in the hierarchical order. Negotiated and sub-ordinated masculinity are at the lower rung in the hierarches of masculinities in Paatal Lok.

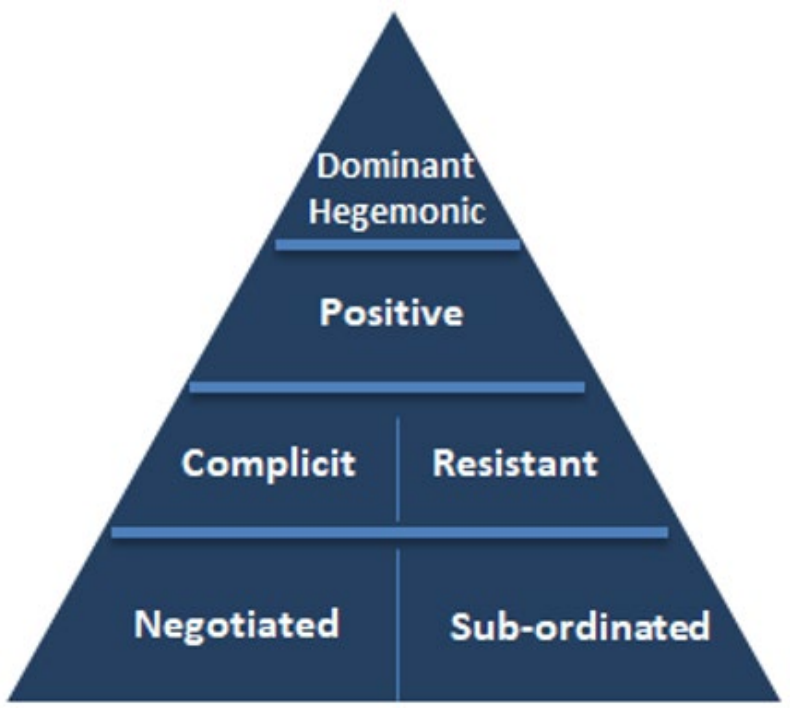

Figure 2. Hierarchies of Masculinities in Paatal Lok

\section{RECOMMENDATIONS AND CONCLUSION}

While it is heartening to note that Indian streaming media showcases a variety of masculinities, it should also be noted that dominance of the powerful over the weak within masculinities; marginalization of the third gender and a strong patriarchal mind-set runs through the hierarchy and is reinforced through the show. It is recommended that Indian streaming media highlight positive masculinity through its shows. It is also recommended that patriarchal values and sexist slurs as an expression of manhood should be avoided. It would also help if the third gender is presented in a more empowered way. The show reinforces existing gender norms of violence and power as the prerogative of successful men. This can give way to a humane, gender equal approach to masculinities across the spectrum.

Author contributions: All authors were involved in concept, design, collection of data, interpretation, writing, and critically revising the article. All authors approve final version of the article.

Funding: The authors received no financial support for the research and/or authorship of this article.

Declaration of in terest: Authors declare no competing interest.

Data availability: Data generated or analysed during this study are available from the authors on request.

\section{REFERENCES}

Banerjee, D. (2020, May, 23) Caste, Class and Populist Political Anxieties in 'Paatal Lok'. thewire.in. https://thewire.in/film/caste-class-andpopulist-political-anxieties-in-paatal-lok

Bhasin, K. 2006. What Is Patriarchy. Women Unlimited.

Budig, M., \& Jones, K. (2008). Feminist Theory. In V. Parrillo (Ed.), Encyclopedia of Social Problems. Sage.

Connell, R.W. (1987). Gender and Power: Society, the Person, and Sexual Politics. Cambridge: Polity Press.

Cutler, K. A. (2007). Multiple masculinities?: A content analysis of men in the print media (Master of Sociology), Department of Socology. https://citeseerx.ist.psu.edu/viewdoc/download?doi=10.1.1.428.3 $697 \&$ rep=rep $1 \&$ type $=$ pdf

Darwin, H. (2017). Doing gender beyond the binary: A virtual ethnography. Symbolic Interaction, 40(3), 317-334. https://doi.org/ $10.1002 /$ symb.316

Devi, M. L. (2018). Gender stereotypes in the media: A case study of gender stereotyping phenomenon in Manipuri Media. Journal of Research in Humanities and Social Science, 6(9), 36-41.

Engstrom, E. (2016). Television's Masculinities: "New Man" Portrayals in NBC's "Parks and Recreation" [Paper presentation]. Annual meeting of the Association for Educationin Journalism and Mass Communication, Minneapolis, MN.

Gupta, S. (2020, May 17). Paatal Lok review: An intelligently written, engrossing series. The Indian Express. https://indianexpress.com/ article/entertainment/web-series/paatal-lok-review-anengrossing-series-6410775/

Loncar, M., Šuljug Vučica, Z., \& Nigoević, M. (2016). Constructing masculinity through images: Content analysis of lifestyle magazines in Croatia. International Journal of Social, Behavioral, Educational, Economic, Business and Industrial Engineering, 10, 3123-3126. 
Malik, E. (2020, May 15). Paatal Lok: Journey to the dark side. The Indian Express. https://indianexpress.com/article/entertainment/ opinion-entertainment/paatal-lok-journey-to-the-dark-side6410626/

Mambrol, N. (2017, November 4). Masculinity/Masculinities. Literary Theory and Criticism. https://literariness.org/2017/11/04/ masculinity-masculinities/

Mathew, S. (2020, March 24). COVID-19: Spike in eyeballs on OTT services Netflix, Prime Video. the quint. https://www.thequint.com/ entertainment/hot-on-web/netflix-prime-video-hotstarviewership-coronavirus-covid-19

McQuail, D. (2010). Mcquail's mass communication theory. Sage Publications.

Miller, B. D. (1993). Sex and gender hierarchies. Cambridge University Press.

Moss, M. H. (2012). The media and models of masculinity. Lexington Books.

Neuman, W. L. (2007). Basics of social research: Qualitative and quantitative approaches. Pearson.

Pascoe, C. (2007). Making masculinity: Adolescence, identity, and high school. In Dude, you're a fag: Masculinity and sexuality in high school (pp. 1-24). University of California Press. https://doi.org/10.1525/9780520941045

Rushton, A., Gray, L., Canty, J., \& Blanchard, K. (2019). Beyond binary: (Re)defining "gender" for 21st century disaster risk reduction research, policy, and practice. International Journal of Environmental Research and Public Health, 16(20), 3984. https://doi.org/10.3390/ijerph16203984
Sociology. (n.d.). Hegemonic Masculinity. http://sociology.iresearchnet. $\mathrm{com} /$ sociology-of-gender/hegemonic-masculinity/

Susilo, D. (2017). Masculinity discourse on media text: A critical review about news about violence on online news portals. Masyarakat, Kebudayaan dan Politik, 30(4), 344-352. https://doi.org/10.20473/mkp.V30I42017.344-352

Trujillo, N. (1991). Hegemonic masculinity on the mound: Media representations of Nolan Ryan and American sports culture. Critical Studies in Mass Communication, 8(3), 290-308. https://doi.org/10.1080/15295039109366799

Verma, S. (2018, July 10). Are Web Series Better Than TV Shows? Medium.com. https://medium.com/@supriya.webfare/are-webseries-better-than-tv-shows-799e7a081936

Von Doellinger, O. (2018). From gender binarism to gender... binarism: Gender identity and new expressions of gender stereotypes. International Journal of Clinical Neurosciences and Mental Health, 5, 7. https://doi.org/10.21035/ijcnmh.2018.5.7

Webster, M. Jr., \& Rashotte, L. S. (2009). Fixed roles and situated actions. Sex Roles: A Journal of Research, 61(5-6), 325-327. https://doi.org/10.1007/s11199-009-9606-8

Wong, Y. J., Steinfeldt, J. A., Speight, Q. L., \& Hickman, S. J. (2010). Content analysis of psychology of men \& masculinity (2000-2008). Psychology of Men \& Masculinity, 11(3), 170-181. https://doi.org/10.1037/a0019133 